\title{
ESCOLAS PÚBLICAS E VALORIZAÇÃO DA FORMAÇÃO DOCENTE EM BIOLOGIA NA UFRN
}

\author{
PUBLIC SCHOOLS AND ENHANCEMENT OF TEACHER TRAINING \\ IN BIOLOGY AT UFRN
}

\section{ESCUELAS PÚBLICAS Y LA MEJORA DE LA FORMACIÓN DEL PROFESORADO DE BIOLOGÍA EN UFRN}

\section{Marlécio Maknamara ${ }^{1}$ \\ Rute Alves de Sousa ${ }^{2}$}

\begin{abstract}
RESUMO: O artigo relata experiências de valorização das atividades de estágio supervisionado inspiradas em cotidianos escolares. O objetivo foi aprimorar a formação profissional de futuros docentes de Biologia por meio da consolidação dos estágios supervisionados de formação de professores. O trabalho foi desenvolvido por permanente orientação para a troca e análise de informações sobre a realidade escolar, no sentido de aperfeiçoamento da prática pedagógica dos licenciandos e visando a melhoria dos componentes curriculares envolvidos. Os resultados apontaram para uma dinamização e positivação das atribuições e atividades formativas dos licenciandos. Pudemos concluir que a valorização e a profissionalização da oferta dos componentes curriculares envolvidos possibilitaram aos estagiários melhores condições de formação docente e de conhecimento e intervenção nos cotidianos das escolas-campo de estágio.
\end{abstract}

PALAVRAS-CHAVE: Estágio supervisionado. Cotidianos escolares. Profissionalização docente.

ABSTRACT: This article reports an experience of valorization of the supervised internship activities, inspired by the daily school. The aim was to improve the training of future teachers of biology through consolidation of supervised teacher training. The work was developed through ongoing guidance to the exchange and analysis of information about the school reality, towards improvement of pedagogical practices of the graduating, aiming the improvement of curriculum components involved. The results pointed to a dynamization and positivation of the tasks and training activities by the undergraduates. We concluded that the value of the offer and the professionalization of the curriculum components involved enabled the trainees better teacher training and knowledge of everyday school-training field.

KEYWORDS: Supervised internship. Daily school. Teacher professionalization.

\footnotetext{
${ }^{1}$ Doutor em Educação pela Universidade Federal de Minas Gerais - UFMG, Minas Gerais, MG - Brasil. Professor do Programa de Pós-Graduação em Educação da UFRN. Membro do grupo de pesquisa Ensino de Ciências e Cultura e do GECC - Grupo de Estudos e Pesquisas em Currículo e Culturas/UFMG Minas Gerais, MG - Brasil. E-mail: maknamara@pq.cnpq.br.

${ }^{2}$ Doutora em Psicobiologia pela Universidade Federal do Rio Grande do Norte - UFRN, Natal, RN - Brasil. Professora do Departamento de Práticas Educacionais e Currículo da UFRN, Natal, RN - Brasil. E-mail: ruteasousa@yahoo.com.br.
}

Recebido em: 05/05/2015 - Aprovado em: 03/12/2015. 
RESUMEN: El artículo da cuenta de las experiencias de mejora de las actividades de prácticas supervisadas inspirado en los cotidianos de la escuela. El objetivo fue mejorar la formación de los futuros profesores de Biología por la consolidación de la práctica supervisada de la formación docente. El estudio fue realizado por el foco permanente en el intercambio y análisis de información sobre la realidad escolar en el sentido de la mejora de la práctica pedagógica de los estudiantes y con el objetivo de mejorar los componentes del plan de estudios involucrados. Los resultados apuntan a una dinámica y positivación de las tareas y actividades de formación de los estudiantes de pregrado. Llegamos a la conclusión de que la recuperación y la profesionalización de la oferta de componentes curriculares involucrados permitió a los alumnos mejores condiciones para su formación y para, el conocimiento y la intervención con los cotidianos de las escuelas de campo.

PALABRAS CLAVE: Prácticas supervisadas. Cotidianos escolares. Profesionalización docente.

\section{INTRODUÇÃO}

O curso de Licenciatura em Ciências Biológicas da UFRN (Universidade Federal do Rio Grande do Norte) foi reconhecido pelo Decreto n. ${ }^{\circ} 79.627$, de 28/4/1977, e o seu currículo original foi modificado em uma ampla reforma no ano de 1980. Naquele tempo os alunos deveriam cursar obrigatoriamente as disciplinas Prática de Ensino de Biologia (com carga horária de 180 horas) e Prática de Ensino de Ciências Físicas e Biológicas (com 135 horas). Essa carga horária de estágio perdurou até 2009 quando, seguindo a Resolução CNE/CP n. ${ }^{\circ} 2$ de 2002 (BRASIL, 2002), os estágios de formação de professores na UFRN passaram às 400 horas previstas nacionalmente para os cursos de formação de professores da Educação Básica.

Para além da carga horária, as recentes reformas nos cursos de licenciatura no Brasil também têm induzido um redimensionamento dos estágios curriculares supervisionados quanto às suas finalidades. Termos como "treinamento", "prática", "ensino", "orientação", "supervisão", "observação", "intervenção", "valorização", "qualidade", "profissionalização", "(auto)formação" - entre tantos usados para dizer e fazer parte dos estágios supervisionados de formação de professores - dão a tônica de um contexto (novo?) no qual se assumem e fazem assumir significados variados para as docências, as escolas, as universidades e para as relações que entre elas podem ser estabelecidas.

Na Universidade Federal do Rio Grande do Norte, o Projeto do Curso de Licenciatura em Ciências Biológicas passou a reservar um conjunto de componentes curriculares (PEC0179, PEC0180, PEC0181 e PEC0182 ${ }^{i}$ ) ofertados pelo Departamento de Práticas Educacionais e Currículo, e voltados especificamente a diferentes dimensões do pensar e executar as aprendizagens da docência nos Ensinos Fundamental e Médio (UFRN1, s/d). Entretanto, a institucionalização de tais componentes tem enfrentado desafios, seja pela sua recente implantação, seja pela dificuldade de licenciandos e escolas que os recebem em se desvencilharem da antiga concepção de estágio como "prática do ensino", como mero treinamento na ministração de aulas. 
Há, portanto, um problema de concretização curricular de tais estágios, cujos desafios repercutem tanto na sua realização com as escolas e com os componentes que lhes são correlatos, quanto na formação dos futuros docentes de Biologia. No presente texto, nosso objetivo é relatar algumas das experiências que temos tido na orientação de tais estágios, focando a discussão nas contrapartidas que temos dado a uma formação docente pautada na valorização das escolas públicas potiguares.

\section{O COMPONENTE PEC0179 FAZENDO-SE ESTÁGIO COM ESCOLAS PÚBLICAS}

O Estágio Supervisionado de Formação de Professores I (Ciências Biológicas) possui carga horária total de cem horas e tem em sua ementa os seguintes tópicos de conteúdo: “Orientações gerais para os Estágios Supervisionados de Formação de Professores. Observação da instituição escolar: realidade socioeconomica e gestão. Projeto PolíticoPedagógico da Escola e o lugar do componente curricular nessa proposta. Políticas educacionais" (UFRN2, s/d). Como se vê, trata-se de um componente-chave na formação docente em Ciências e Biologia, porque introdutório aos estágios supervisionados na Licenciatura em Ciências Biológicas, além de representar um momento privilegiado de imersão dos licenciandos nos cotidianos escolares.

Em atenção às demandas de PEC0179, em 2012 foi proposto à Pró-Reitoria de Graduação da UFRN um projeto de melhoria das atividades de estágio supervisionado, inspiradas em cotidianos escolares. Intitulado "Pelos caminhos da escola: valorização das atividades de estágio supervisionado na formação docente em Biologia" o projeto partiu do pressuposto de que o aprimoramento da formação docente na licenciatura também passa pela consolidação dos seus estágios supervisionados, incluindo uma necessidade de imersão, conhecimento e participação nos/dos/com os cotidianos escolares. Tal projeto previa ainda que, além de dinamizar a operacionalização daquele componente curricular, poderia ajudar a fazer frente a um "desprestígio acerca dos estágios" (UFRN, 2012) que vinha sendo notado.

Em se tratando de fazer frente a tal desprestígio, reconhecíamos ser impossível, por melhores que fossem as intenções, creditarmos a um projeto de ensino o privilégio daquele enfrentamento. Mas por entendermos que nossa proposta ultrapassava o treinamento de monitores e a sua iniciação à docência universitária (o que não era pouco), inserindo-se em um horizonte político maior, perseguimos em PEC0179 alguns princípios e possibilidades. São eles: entendimento das escolas públicas como espaços privilegiados de formação docente (CANÁRIO, 2006); compreensão de que não existe "a escola pública", mas discursos que procuram generalizar entendimentos sobre tais escolas e apagar as multiplicidades de seus cotidianos (ALVES e OLIVEIRA, 2005), entre eles o discurso neoliberal e sua forma particular de ver e dizer a crise educacional pela qual estaríamos passando (GENTILI, 1995); reconhecimento de que tal "crise da escola" é também uma crise da capacidade de pensar as escolas (CANÁRIO, 2005), capacidade esta que se pode ver traduzida nos pensamentos que 
uma escola faz de si mesma em seu projeto político-pedagógico (LIBÂNEO, 2008); descobrir que há muito que observar -“ouvir/ler/sentir/cheirar" - em uma escola (ALVES, 1998) e que as múltiplas experiências que formatam as vozes dos sujeitos da educação escolar precisam ser conhecidas (McLAREN, 1997), sobretudo em se tratando de passar de uma "curiosidade ingênua" a uma "curiosidade epistemológica" (FREIRE, 2011); conhecer lugares diferenciais de Ciências e de Biologias (MARANDINO; SELLES; FERREIRA, 2009) e também aí "cultivar algum descontentamento com aquilo que temos feito de nós" (AQUINO, 2007, p. 65); e com tudo isso aprender, enfim, que é possível ser otimista em relação às escolas e seus sujeitos (FERRAÇO, 2004).

Tendo em vista esses cenários possíveis, o projeto em questão tem primado por possibilitar aos discentes aproximar-se dos cotidianos escolares mediante diferentes frentes de observação das escolas públicas escolhidas como campo de estágio. A cada semana, os estagiários relatam publicamente em sala de aula na UFRN suas experiências de observação nas escolas-campo ${ }^{\mathrm{ii}}$ de estágio, enquanto se preparam para prosseguir com as instruções para novas observações a serem feitas na semana seguinte. A cada frente de observação corresponde um objetivo específico: compreender o funcionamento de uma escola a partir das suas formas de gestão; compreender o funcionamento da escola por meio das marcas deixadas em seu espaço; aproximar-se do cotidiano escolar por meio das vivências dos estudantes e da convivência com eles/elas; aproximar-se do cotidiano escolar por meio das vivências dos estudantes, segundo a voz de seus docentes; identificar modalidades de organização curricular em Ciências e Biologia nas escolas-campo de estágio; pesquisar um fenômeno da educação escolar, segundo diferentes tipos de sujeitos a ela correlatos.

Assim sendo, as aulas e demais atividades de PEC0179 dão cabo aos seguintes questionamentos: o que salta aos olhos de quem observa uma escola pública? O que se pode apreender da escola-campo de estágio ao se observar seu Projeto Político Pedagógico? E ao se analisar o uso que se faz dos seus lugares e espaços? Quem são os estudantes das escolas públicas analisadas? Quem são eles segundo seus docentes? De que forma nelas se dá a organização curricular em Ciências e Biologia? Embora reconhecendo ser impossível abarcar em um componente curricular a complexidade dos cotidianos escolares, tais frentes de observação, de um modo ou de outro, procuram contemplar aquilo que Saviani (2007) reconhece como aspectos constitutivos das instituições escolares: a materialidade (o instituído, a escola instalada), a representação (a institucionalização, os sentidos atribuídos à escola) e a apropriação (a instituição em ato, a materialização de ideários e práticas pedagógicas).

Além de tais perguntas, a cada semestre é eleita uma questão de pesquisa tendo como objetivo a sondagem de um fenômeno específico da educação escolar segundo as vozes de diferentes tipos de sujeitos das escolas-campo de estágio. Por meio dessas pesquisas os licenciandos, em equipes na sala de aula na UFRN, analisam qualitativamente o material empírico resultante da sondagem, o que contribui significativamente para os propósitos de PEC0179 e do projeto aqui relatado. Também por meio dessas sondagens articulamos as atividades dos semestres anteriores àquelas dos semestres em curso: assim como os 
licenciandos de 2012.2 abordaram a pesquisa "Para que serve uma escola?" e apresentaram os resultados nos semestres de 2013.1 e 2013.2, os licenciandos do semestre de 2013.1 apresentaram os dados da pesquisa "O que é uma escola de qualidade?" no semestre posterior, e assim por diante. Como resultado desse esforço questionador e investigativo temos interagido com 34 escolas (municipais e estaduais, mencionadas anteriormente), ainda que de modo diferencial entre elas, ao longo desses semestres, desde 2012.

\section{PEC0180, PEC0181 E PEC0182: MULTIPLICIDADES DE INTERVENÇÕES E REGÊNCIAS}

O "Estágio Supervisionado II" traz em sua ementa um direcionamento para a ampliação da participação ativa do licenciando na vida da escola e da comunidade, com o acompanhamento das reuniões pedagógicas e dos conselhos escolares, além da elaboração e desenvolvimento de projetos de integração escola/comunidade. O cumprimento dessa ementa é um grande desafio, pois ele exige uma maior aproximação entre a Universidade e a escola para que aconteça de fato, pois o estagiário tem dificuldade para se inserir no cotidiano escolar sem a intervenção ou o acompanhamento de um profissional dentro da própria escola. Além disso, a própria escola tem dificuldade de fazer um trabalho colaborativo com a comunidade, embora atualmente tenhamos várias iniciativas bem sucedidas (MENIN; SILVA, 2012; ABRAMOVAY, 2003; ASSUMPÇÃO, 2005).

Durante o PEC0180 os estagiários são orientados a adentrarem o ambiente escolar de modo a conhecer e acompanhar os processos de interação entre a escola e a comunidade. Em algumas escolas o calendário de reuniões de pais ou dos conselhos escolares não é agendado antecipadamente e quando ele existe os estagiários não tomam conhecimento, embora estejam na escola uma vez por semana. Essa falta de comunicação / interação entre o estagiário e a escola impede que os estagiários realizem as atividades propostas pela disciplina e empobrecem as discussões / reflexões realizadas na sala da universidade sobre as interações entre a escola e a comunidade.

Apesar disso, nesses poucos anos que atuamos no componente curricular PEC0180, temos vivenciado algumas experiências de projetos de intervenção bem interessantes que contribuem positivamente para a aproximação entre a Universidade e as escolas. Dentre os projetos realizados, Sousa (2013) destacou:

- Revitalização do laboratório de Biologia de uma escola estadual - Essa escola tem um grande laboratório com muita vidraria e reagentes, no entanto, ele vinha sendo utilizado como depósito e os estagiários tiveram muito trabalho para deixá-lo em condições de uso. No final o trabalho foi reconhecido pela escola e foi motivo de satisfação para os estagiários que elaboraram e entregaram um Manual com experimentos que poderiam ser realizados no laboratório;

- Pesquisa com os estudantes no pátio da escola - Esse projeto tinha como objetivo identificar os motivos pelos quais os estudantes do ensino básico dessa escola "gazeavam" as 
aulas. Os estagiários se incomodaram com o grande número de alunos que ficavam no pátio da escola durante o horário de aula e resolveram, junto com a coordenação pedagógica, realizar uma pesquisa com o intuito de identificar os motivos pelos quais os alunos preferiam ficar fora da sala de aula. A pesquisa foi realizada durante quase 30 dias e mostrou vários dados interessantes, que podem ser trabalhados pela escola;

- Feira de Ciências - O objetivo desse projeto foi organizar uma feira de ciências na escola. Os estagiários assumiram a organização orientando os trabalhos de todos os alunos das turmas do Ensino Fundamental II. O projeto foi bem aceito pela comunidade escolar, principalmente pelos estudantes, que mostraram grande envolvimento. A distribuição dos temas nas salas, a organização dos grupos e a forma como os estudantes apresentavam os trabalhos foram levados para discussão em sala de aula e teve grande importância no processo de formação dos estagiários a partir da reflexão do que tinha sido visto na prática desenvolvida;

- Dez motivos para plantar uma árvore - O objetivo desse projeto foi despertar o interesse dos alunos pelas questões ambientais. Para isso os estagiários realizaram palestras e oficinas sobre o tema e fizeram plantio de mudas com os alunos. Percebeu-se o grande envolvimento dos estudantes com o projeto e a satisfação da escola e dos estagiários com os resultados obtidos;

- Consciência no intervalo - Este projeto teve como objetivo despertar o interesse dos alunos pela Ciência a partir dos horários ociosos. Os estagiários queriam desenvolver um projeto que utilizasse o horário do intervalo, quando os alunos estariam mais ociosos. $\mathrm{O}$ projeto foi realizado em dois momentos em cada um dos dois turnos. Os estagiários abordaram temas como sexualidade e drogas, e foram prestigiados por um número significativo de alunos que se aproximavam e questionavam sobre os assuntos abordados.

Já nos estágios supervisionados de formação de professores para os ensinos Fundamental e Médio (PEC0181 E PEC0182), aos poucos tem se consolidado uma carga horária mínima de regência que possibilita aos alunos passarem mais tempo no ambiente escolar e vivenciarem as dificuldades de trabalhar os conteúdos pedagógicos e as atividades avaliativas. No início do semestre o aluno é encaminhado às escolas para realizar a formalização do estágio e iniciar, com o professor supervisor, o planejamento da regência. Normalmente o planejamento do estagiário fica refém do planejamento do professor supervisor, com pouca ou nenhuma possibilidade de interferência, o que impede que o estagiário desenvolva estratégias inovadoras. O problema é que a maior parte dos nossos professores supervisores utiliza exclusivamente o livro didático em suas aulas. Isso é preocupante, uma vez que os estagiários estão iniciando a vivência na escola e podem levar esse "aprendizado" para a vida profissional (RODRIGUES, 2013). Entretanto, nos casos em que o professor supervisor dá autonomia ao estagiário para realizar o seu trabalho, verificamse ganhos significativos. Para ilustrar esses fatos serão relatados aqui dois casos específicos.

O primeiro diz respeito ao estágio desenvolvido em dupla em uma turma de $3^{\circ}$ ano do Ensino Médio explorando conteúdos de genética. Apesar da vivência na escola, em estágios \begin{tabular}{l|l|l|l|l|l|l} 
(C) ETD - Educ. Temat. Digit. & Campinas, SP & v.18 & n.1 & p. 215-226 & jan./abr. /2016 & ISSN 1676-2592
\end{tabular} 
anteriores, os estagiários ficaram surpresos com as dificuldades enfrentadas pelos estudantes em relação ao conteúdo trabalhado. Eles utilizaram estratégias diversificadas durante a regência, realizaram vários exercícios para ajudar os estudantes a compreenderem o conteúdo, tiveram a liberdade para elaborar, aplicar e corrigir a atividade avaliativa, entretanto, o desempenho dos estudantes foi considerado muito baixo. Após analisarem a situação e conversar com a professora supervisora, ficou definido que eles deveriam elaborar e aplicar outra atividade avaliativa, dessa vez com o acompanhamento da professora orientadora de estágio. Os resultados da segunda atividade avaliativa foram melhores e possibilitaram aos estagiários refletirem sobre as dificuldades inerentes à elaboração dessa ferramenta, assim como sobre a importância da avaliação no processo de ensino e aprendizagem. Essa experiência, embora seja bem significativa para a formação do professor, nem sempre é possível de se realizar no ambiente escolar por diversos fatores, entre eles, o distanciamento entre supervisor e universidade.

Outra experiência significativa foi realizada por um estagiário em uma escola municipal em uma turma de oitavo ano do Ensino Fundamental. Nesse caso, a professora supervisora já recebe estagiários da UFRN há alguns anos e normalmente deixa-os bem à vontade para realizarem a regência, acompanhando o desenvolvimento deles e complementando quando necessário. $\mathrm{O}$ que se pretende destacar nesse caso é a autonomia do estudante em sugerir mudanças na sequência de conteúdos que seria abordada e o fato de as mudanças terem sido acatadas pela professora. A proposta do estagiário foi iniciar a regência com o sistema nervoso, seguido pelos órgãos de sentidos e sistema endócrino. Ao ser questionado do porquê da mudança, ele apresentou uma justificativa consistente, no entanto, o mesmo pretendia a partir do sistema endócrino fazer uma interação com o sistema digestório e finalizar o estágio com o sistema reprodutor. Nesse caso ao ser questionado do porquê trabalhar o sistema reprodutor após o sistema digestório e não antes, a justificativa dada foi que a professora supervisora gostaria que ele trabalhasse essa temática. Isso mostra a fragilidade na organização da sequência didática dos conteúdos não apenas do estagiário, mas também da supervisora, que acatou as sugestões sem questionar. Esse episódio possibilitou uma reflexão sobre a importância de que no planejamento os conteúdos sejam abordados considerando-se as interações entre eles e uma sequência lógica, fazendo com que o estagiário revisse o seu planejamento e tivesse segurança pedagógica para justificar suas escolhas.

As duas experiências relatadas foram significativas em razão da abertura do professor supervisor para ouvir o estagiário e permitir intervenções, e, este, por sua vez, dialogou com o professor na universidade que pode orientar a sua atuação. Porém, nem sempre é assim que o estágio se desenvolve e a relação entre escola e universidade está longe de ser adequada (MARTINS, 2009; RODRIGUES, 2013; SILVA; SCHNETZLER, 2008; SOUSA et al., 2015). No trabalho que Rodrigues (2013) realizou no Piauí se verifica a insatisfação dos professores supervisores com a ausência dos professores universitários na escola. Por sua vez, Sousa e colaboradores (2015) reclamam da dificuldade que o estagiário tem de se integrar ao ambiente escolar e Martins (2009) expõe a ausência do professor colaborador durante a 
regência do estagiário e a desmotivação desse profissional no ambiente de trabalho. Por fim, ressaltamos que, segundo Silva e Schnetzler (2008), o Brasil precisa instituir políticas públicas que definam o papel das escolas, do licenciando e dos professores supervisores da rede básica na formação dos futuros professores.

\section{CONSIDERAÇÕES FINAIS}

As atividades de orientação de estágio aqui elencadas somam-se a um esforço da UFRN em melhorar a qualidade das atividades acadêmicas de maneira "integrada à realidade social e articulada à prática profissional” (UFRN, 2011, p. 16). Com o Programa Reuni, o quadro de docentes do Departamento de Práticas Educacionais e Currículo (DPEC) envolvidos com estágios supervisionados de formação de professores foi ampliado.

Atualmente, nos estágios da Licenciatura em Ciências Biológicas temos dois professores efetivos com formação específica e pedagógica atuando com dois docentes temporários (que também atuam no Curso de Pedagogia), possibilitando a organização de um grupo de profissionais que se reúnem periodicamente para pensar o planejamento, a orientação e o acompanhamento de tais estágios, tendo em vista a importância dos mesmos na formação inicial dos professores.

Temos feito muito e desejamos fazer mais. Neste 2014.2, o grupo de docentes do DPEC responsáveis por estágios em três diferentes licenciaturas presenciais (Ciências Biológicas, Física e Química) decidiu concentrar seus esforços em escolas que têm revelado um envolvimento mais intenso e compromissado com a formação docente, na supervisão dos estágios e/ou na recepção de grupos PIBID (Programa Institucional de Bolsa de Iniciação à Docência). Avaliamos que as mais de 30 escolas com as quais interagimos nos últimos dois anos somente no âmbito dos estágios presenciais do curso aqui em foco dão conta da dimensão do nosso trabalho, mas sinalizaram a necessidade de revisão e aperfeiçoamento de tal trabalho de interlocução com a rede pública de ensino. Trabalho que fica imensamente ampliado quando passam a ser considerados os universos escolares atendidos pelos outros três estágios de formação de professores que compõem a Licenciatura em Ciências Biológicas/EaD (UFRN3, s/d), em seus diferentes polos de atendimento.

Em sua diversidade de políticas e práticas junto aos componentes curriculares aqui mencionados, tal quadro de docentes assume e concretiza o entendimento de que "só é possível defendermos a escola pública se defendermos a sua renovação" (NÓVOA, 2012, p. 13). Por entender que tal renovação das escolas públicas passa por elas, mas vai além delas mesmas, nos estágios sob nossa responsabilidade buscamos ver em desuso termos como "perda de tempo", “obstáculo", “espera", "medo", "angústia”, “dúvida”, “desprezo", "impaciência", "descrença", "negação", "desvalorização" - não para facilitarmos nossa atuação profissional, mas para que solidariedade, beleza, esperança, êxito e mudança também possam ser vistos, ditos e fazer parte dos cotidianos escolares com os quais temos partilhado nossas aprendizagens. 


\section{REFERÊNCIAS}

ABRAMOVAY, Miriam (Coord.). Escolas inovadoras: experiências bem-sucedidas em escolas públicas. Brasília: UNESCO, 2003. 428 p. Disponível em: 〈 http://goo.gl/JpRgN2〉. Acesso em: 05 mai. 2015.

ALVES, Nilda. O espaço escolar e suas marcas: o espaço como dimensão material do currículo. Rio de Janeiro: DP\&A, 1998. 152 p.

ALVES, Nilda; OLIVEIRA, Inês Barbosa. Uma história da contribuição dos estudos do cotidiano escolar ao campo do currículo. In: LOPES, Alice Casemiro; MACEDO, Elizabeth. (Org.) Currículo: debates contemporâneos. São Paulo: Cortez, 2005. p.78-102.

AQUINO, Julio Groppa. Instantâneos da escola contemporânea. Campinas: Papirus, 2007. $128 \mathrm{p}$.

ASSUMPÇÃO, Tânia Mara Testaí. Reflexões sobre a escola e sua interação com a comunidade: um estudo de caso. 2005. 115 f. Dissertação (Mestrado em Educação) - Centro de Ciências da Educação, Universidade Federal de Santa Catarina, Florianópolis, SC, 2005. Disponível em: 〈 http://goo.gl/3vlp1v〉. Acesso em: 05 mai. 2015.

BRASIL. Conselho Nacional de Educação. Resolução CNE/CP 2/2002. Diário Oficial da União, Brasília, 4 de março de 2002. Seção 1, p. 9. Disponível em: 〈 http://goo.gl/3UOyB $\rangle$. Acesso em: 05 mai. 2015.

CANÁRIO, Rui. O que é a escola? Um “olhar” sociológico. Porto: Ed. Porto, 2005. 208 p.

CANÁRIO, Rui. A escola tem futuro? Das promessas às incertezas. Porto Alegre: Artmed, 2006.

FERRAÇO, Carlos Eduardo. Os sujeitos praticantes dos cotidianos das escolas e a invenção dos currículos. In: MOREIRA, Antônio Flávio Barbosa; PACHECO, José Augusto;

GARCIA, Regina Leite. (Org.). Currículo: pensar, sentir e diferir. Rio de Janeiro: DP\&A, 2004, v. 1, p. 77-94.

FREIRE, Paulo. Pedagogia da autonomia: saberes necessários à prática educativa. 43. ed. São Paulo: Paz e Terra, 2011. 143 p.

GENTILI, Pablo. Como reconhecer um governo neoliberal? Um breve guia para educadores. In: SILVA, Luiz Heron da; AZEVEDO, José Clóvis de (Org.). Reestruturação curricular: teoria e prática no cotidiano da escola. Petrópolis: Vozes, 1995. p. 128-137.

GUATTARI, Félix. As três ecologias. 17. ed. Campinas: Papirus, 2006. 56 p.

LIBÂNEO, José Carlos. Organização e gestão da escola: teoria e prática. 5. ed. Goiânia: MF Livros, 2008. 319 p. 
MARTINS, André Ferrer Pinto. Estágio supervisionado em física: o pulso ainda pulsa... Revista Brasileira de Ensino de Física, São Paulo, SP, v. 31, n. 3, p. 3402-3407. 2009. Disponível em: < http://goo.gl/6MpTyB >. Acesso em: 05 mai. 2015. ISSN 1086-9126.

MARANDINO, Martha; SELLES, Sandra Escovedo; FERREIRA, Marcia Serra. Ensino de Biologia: histórias e práticas em diferentes espaços educativos. São Paulo: Cortez, 2009. $215 \mathrm{p}$.

McLAREN, Peter. A vida nas escolas: uma introdução à pedagogia crítica nos fundamentos da educação. 2. ed. Porto Alegre: Artmed, 1997. 353 p.

MENIN, Maria Suzana de Stefano; SILVA, Claudiele Carla Marques. Análise das relações entre escola, comunidade e educação moral. In: SEMINÁRIO DE PESQUISA EM EDUCAÇÃO DA REGIÃ̃ SUL. 9, Caxias do Sul, 2012. Disponível em: < http://goo.gl/4XnqUz >. Acesso em: 05 mai. 2015. ISSN 2238-9229.

NÓVOA, António. Pensar alunos, professores, escolas, políticas. Educação, Cultura e Sociedade, Sinop, MT, v. 2, n. 2, p. 07-17. 2012. Disponível em: 〈 http://goo.gl/SmIYxO $>$. Acesso em: 05 mai. 2015. ISSN 2237-1648.

RODRIGUES, Micaías Andrade. Quatro diferentes visões sobre o estágio supervisionado. Revista Brasileira de Educação, Rio de Janeiro, v. 18, n. 55, p. 1009-1034. 2013. Disponível em: < http://goo.gl/LgQHz0>. Acesso em: 05 mai. 2015. ISSN 1809-449X.

SAVIANI, Dermeval. Instituições escolares no Brasil: conceito e reconstrução histórica. In: NASCIMENTO, Maria Isabel Moura; SANDANO, Wilson; LOMBARDI, José Claudinei; SAVIANI, Dermeval (Org.). Instituições escolares no Brasil: conceito e reconstrução histórica. Campinas: Autores Associados, 2007. p. 3-27.

SILVA, Rejane Maria Ghisolfi da; SCHNETZLER, Roseli Pacheco. Concepções e ações de formadores de professores de Química sobre o estágio supervisionado: propostas brasileiras e portuguesas. Química Nova, São Paulo, v. 31, n. 8, p. 2174-2183. 2008. Disponível em: < http://goo.gl/tefVGj>. Acesso em: 05 mai. 2015. ISSN 1678-7064.

SOUSA, Rute Alves. Reflexão e pesquisa no estágio supervisionado: uma experiência no curso de ciências biológicas. Enseñanza de las Ciencias, Barcelona, ES, 2013. p. 128-132. ISSN 0212-4521.

SOUSA, Rute Alves; LUCAS, Daniela Santos; ARAÚJO, Elane Fábia; FRANÇA, Paulo Ricardo; SILVA, Roseane Pereira. Formação inicial do professor e o processo de inserção do estagiário nas escolas campo de estágio. In: III ENCONTRO REGIONAL DE ENSINO DE BIOLOGIA. Juiz de Fora, MG, 2015.

UNIVERSIDADE FEDERAL DO RIO GRANDE DO NORTE, Departamento de Práticas Educacionais e Currículo. Boletim Informativo do DPEC. Natal: UFRN, n. 8, ed. 27 set. 2012. 12 p.

UNIVERSIDADE FEDERAL DO RIO GRANDE DO NORTE. Plano de desenvolvimento institucional: 2010-2019. Natal: UFRN, 2010. 
UNIVERSIDADE FEDERAL DO RIO GRANDE DO NORTE. Plano de gestão 2011-2015 (minuta). Natal: UFRN, 2011.

UNIVERSIDADE FEDERAL DO RIO GRANDE DO NORTE. Estrutura curricular do curso de licenciatura em ciências biológicas. Natal: UFRN, s/d. Disponível em: 〈http://goo.gl/gnj4wk >. Acesso em: 18 nov. 2011.

UNIVERSIDADE FEDERAL DO RIO GRANDE DO NORTE. Componentes curriculares do Departamento de Práticas Educativas e Currículo, Centro de Educação. Natal: UFRN, s/d. Disponível em: 〈https://goo.gl/Ed8bAw〉. Acesso em: 18 nov. 2011.

UNIVERSIDADE FEDERAL DO RIO GRANDE DO NORTE. Projeto do curso de Licenciatura em Ciências Biológicas a Distância. Natal: UFRN, s/d. Disponível em: <http://goo.gl/QJop3e>. Acesso em: 03 dez. 2012. 


\section{Agradecimentos}

Aos monitores Josélia Domingos Pereira (titular), Raniery de Oliveira Santana (voluntário) e Carmem Sara P. de Oliveira (voluntária) somos gratos pela dedicação, responsabilidade e cuidado com que desempenharam suas funções. Também agradecemos aos docentes contratados temporariamente, pelo envolvimento profissional e pelas valiosas colaborações nestes e em outros componentes que assumem conosco na referida instituição.

\footnotetext{
i Respectivamente, os códigos aqui mencionados referem-se a: Estágio Supervisionado de Formação de Professores I (Ciências Biológicas), Estágio Supervisionado de Formação de Professores II (Ciências Biológicas), Estágio Supervisionado de Formação de Professores para o Ensino Fundamental (Ciências Biológicas) e Estágio Supervisionado de Formação de Professores para o Ensino Médio (Ciências Biológicas).

ii EM $4^{\circ}$ Centenário, EE Profa. Ana J. Mousinho, EE Prof. Anísio Teixeira, EE Prof. Josino Macedo, EE Prof. Antônio Fagundes, EM Prof. Otto Guerra, EE Winston Churchill, EM Mário Lira, EE Berilo Wanderley, EE Poeta Castro Alves, EE Jorge Fernandes, EE Walfredo Gurgel, EM Celestino Pimentel, EE Stela Wanderley, EE Floriano Cavalcante, E. E. Dulce Wanderley, EE Prof. José Machado, EE Tiradentes, EE Varela Barca, EE Francisco Ivo Cavalcanti, EE Edgar Barbosa, EE Prof. Zuza, EE União do Povo, EM Terezinha Paulino, EM Vereador José Sotero, EE Nestor Lima, EE Manoel Villaça, EE Instituto Ary Parreiras, EE Ulisses de Gois, CEJA Felipe Guerra, EE Prof. Eliah Rego, EM Antonio Severiano, EE Sebastião Fernandes, EE Josefa Sampaio.
}

\section{Como citar este documento:}

MAKNAMARA, Marlécio. Escolas públicas e valorização da formação docente em Biologia na UFRN. ETD Educação Temática Digital, Campinas, SP, v. 18, n. 1, p. 215-226, abr. 2016. ISSN 1676-2592. Disponível em: 〈http://periodicos.sbu.unicamp.br/ojs/index.php/etd/article/view/8634858>. Acesso em: 05 abr. 2016. doi: 〈http://dx.doi.org/10.20396/etd.v18i1.8634858>. 